\title{
EDITORIAL
}

\section{Relation between blood pressure after an acute coronary event and subsequent cardiovascular risk}

\section{C-K Wong, H D White}

Heart 2002;88:555-558

\begin{abstract}
Evidence is accumulating that after an acute coronary event, assiduous control of both systolic and diastolic pressure is indicated
\end{abstract}

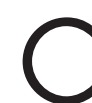
oncepts about the relation between blood pressure and outcomes have evolved over the last 20 years from a sole emphasis on diastolic blood pressure to include both systolic blood pressure ${ }^{1}$ and pulse pressure. ${ }^{23}$ Recently the Framingham heart study has provided further longitudinal data on the natural evolution of blood pressure over a person's lifetime. ${ }^{4}$ The systolic pressure rises linearly between the ages of 30 and 84 years. There is initially a concurrent increase in the diastolic pressure, but between the ages of 50 and 60 years the diastolic pressure begins to decline and the pulse pressure widens steeply. ${ }^{4}$ It has also been shown that in young subjects the brachial systolic pressure is higher than the central aortic systolic pressure, whereas in older subjects ( $>60$ years) this difference disappears. ${ }^{5}$ The explanation for these findings is that there is an age related increase in stiffness accompanied by decreases in the elasticity and compliance of the central conduit arteries, leading to an increased arterial pulse wave velocity and an earlier return of the reflected pressure wave to the aorta. ${ }^{5}$

\section{SYSTOLIC PRESSURE AND PULSE PRESSURE ARE THE MAIN RISK FACTORS} In 2036 subjects aged $50-79$ years in the Framingham heart study, only systolic pressure (and not diastolic pressure) was independently associated with the development of coronary heart disease over the subsequent 20 years. ${ }^{6}$ In patients with systolic pressures of $\geqslant 120 \mathrm{~mm} \mathrm{Hg}$ the coronary heart disease risk actually increased as diastolic pressures decreased, suggesting that a wider pulse pressure was an important component of coronary risk. ${ }^{6}$ A recent report from the Framingham investigators added to this cohort another 4506 subjects from the Framingham offspring study, so that the baseline ages of the combined cohort ranged from 20 to 79 years. ${ }^{2}$ Over 17 years, $12 \%$ of subjects developed coronary heart disease. In subjects whose baseline age was $<50$ years, diastolic pressure was the strongest predictor of the subsequent development of fatal or non-fatal coronary disease, including myocardial infarction and angina pectoris. Between the ages of 50 and 59 years there was a transition period when all three blood pressure measures (systolic pressure, diastolic pressure, and pulse pressure) harveyw@adhb.govt.nz
New Zealand: were comparable predictors of coronary risk. From the age of 60 years, diastolic pressure was inversely related to coronary risk so that the pulse pressure became superior to systolic pressure as a predictor. $^{2}$

In the 1990s a series of placebo controlled trials clearly established the benefits of antihypertensive treatment in patients aged $\geqslant 60$ years with isolated systolic hypertension ( $\geqslant 160 \mathrm{~mm} \mathrm{Hg}$ ). A recent meta-analysis evaluated the relation between vascular risk and systolic pressure. ${ }^{1}$ Over 3.8 years the relative hazard ratios (after adjustment for age, sex, diastolic pressure, and regression dilution bias) associated with a $10 \mathrm{~mm} \mathrm{Hg}$ higher initial systolic pressure were 1.26 for total mortality $(p=0.0001)$ and 1.22 for stroke $(p=0.02)$, but only 1.07 for coronary events $(p=0.37)$. The non-significant increase in coronary events with increases in systolic pressure may be partly explained by the shorter duration of follow up as compared with the Framingham study. ${ }^{26}$ Antihypertensive treatment was associated with a greater absolute benefit in patients with previous cardiovascular complications, those aged $\geqslant 70$ years, and those with wider pulse pressures. ${ }^{1}$

The World Health Organization ${ }^{7}$ and Joint National Committee ${ }^{8}$ reports both recommend that systolic pressure and diastolic pressure should be reduced below target levels. For patients without target organ damage or cardiovascular disease, the target is $140 / 90 \mathrm{~mm} \mathrm{Hg}$. For patients with target organ damage (vascular disease, left ventricular hypertrophy, nephropathy or retinopathy), diabetes or cardiac disease, the target is $130 / 85 \mathrm{~mm} \mathrm{Hg}$. The British Hypertension Society recommends initiation of treatment in patients with cardiovascular disease if the sustained blood pressure is $>140 \mathrm{~mm} \mathrm{Hg}$ systolic or $>90 \mathrm{~mm} \mathrm{Hg}$ diastolic.?

Abbreviations: $A C E$, angiotensin converting enzyme; EUROASPIRE, European action on secondary and primary prevention through intervention to reduce events; EUROPA, European trial on reduction of cardiac events with perindopril in stable coronary artery disease; GUSTO, global use of strategies to open occluded coronary arteries; HOPE, heart outcomes prevention evaluation; HOT, hypertension optimal treatment; LIPID, long-term intervention with pravastatin in ischemic disease; PAMELA, pressioni arteriose monitorate e loro associazioni; PEACE, prevention of events with angiotensin-converting enzyme inhibition; PREVENIR, distribution and treatment of cardiovascular risk factors in coronary patients; QUIET, quinapril ischemic event trial; SAVE, survival and ventricular enlargement; TIMI, thrombolysis in myocardial infarction 


\section{BLOOD PRESSURE CONTROL IS OFTEN SUBOPTIMAL}

In a long term French study which included 4714 middle aged men ( $52 \pm 11$ years) with hypertension documented between 1972 and 1988 , only $14.5 \%$ of patients had effective control of both systolic pressure $(<140 \mathrm{~mm} \mathrm{Hg})$ and diastolic pressure $(<90 \mathrm{~mm} \mathrm{Hg}$ ) measured on one clinic occasion in the supine position after a 10 minute rest, while $70.5 \%$ had uncontrolled values for both systolic and diastolic pressure. Over a follow up period of 14 years, systolic pressure (but not diastolic pressure) was independently related to both cardiovascular mortality and coronary mortality. ${ }^{10}$ Admittedly, these observations may not reflect contemporary practice, and high clinic blood pressure recordings may not adequately document the level of control maintained during normal daily activities. The PAMELA study in the mid 1990s, which monitored blood pressure with 24 hour ambulatory recordings, reported that systolic pressure was uncontrolled in about half of the subjects (average $\geqslant 125 \mathrm{~mm} \mathrm{Hg}$ ) and diastolic pressure was uncontrolled in about one third of the subjects (average $\geqslant 80 \mathrm{~mm} \mathrm{Hg}$ ) when compared with the normal ranges as measured by continuous monitoring. ${ }^{11}$

The EUROASPIRE-II study undertaken in 15 European countries in 1999-2000 evaluated patients 1.4 years after an acute coronary event, ${ }^{12}$ and found that $50 \%$ of them had hypertension (systolic $\geqslant 140 \mathrm{~mm} \mathrm{Hg}$ or diastolic $\geqslant 90 \mathrm{~mm} \mathrm{Hg}$ ). In this issue of Heart, Amar and colleagues ${ }^{13}$ extend these observations in the PREVENIR study of 1247 patients admitted to French coronary care units in January 1998. About one third of patients had uncontrolled blood pressure, particularly systolic pressure ( $\geqslant 140 \mathrm{~mm} \mathrm{Hg}$ ), at the time of hospital discharge after acute myocardial infarction. ${ }^{13}$ The authors comment that the incidence of poorly controlled hypertension may be even greater than they observed because their predischarge blood pressure recordings may have underestimated postdischarge blood pressures after patients resumed their normal daily activities. These findings indicate that hypertension, particularly systolic hypertension, is common in patients with coronary disease, and is often inadequately treated.

\section{DOES SUBOPTIMAL BLOOD PRESSURE CONTROL TRANSLATE INTO ADVERSE OUTCOMES?}

Early and effective control of blood pressure may slow the progression of conduit vessel stiffness, ${ }^{14}$ while poor control may accelerate arterial stiffening and lead to a further rise in systolic pressure. ${ }^{5}$ There is limited information about blood pressure control and outcomes after acute coronary events, whereas there is strong evidence linking blood pressure to outcomes before a coronary event.

The SAVE study enrolled 2231 patients who had an impaired left ventricular ejection fraction following myocardial infarction, and reported that the pulse pressure was a significant predictor of mortality and recurrent myocardial infarction within 42 months after adjustment for age, ejection fraction, mean arterial pressure, sex and other factors including the use of $\beta$ blockers. ${ }^{15}$ In the PREVENIR study, isolated systolic hypertension ( $\geqslant 140 \mathrm{~mm} \mathrm{Hg}$ ) was an independent predictor of an adverse cardiovascular outcome within six months. ${ }^{13}$ It would be interesting to know if the pulse pressure had a similar predictive value in the PREVENIR study.

The poor outcomes associated with poor blood pressure control may be exacerbated by inadequate usage of drugs such as $\beta$ blockers and angiotensin converting enzyme (ACE) inhibitors, which way have other cardioprotective effects besides blood pressure reduction. However, multivariate analysis with adjustment for the treatments used showed that wider pulse pressure in the SAVE study and higher systolic pressure in the PREVENIR study were independent predictors of adverse outcomes.
There are various mechanisms whereby hypertension may be associated with poor outcomes after an acute coronary event. Firstly, it may exacerbate left ventricular dilatation and remodelling after myocardial infarction. Increased left ventricular volumes can cause adverse effects and impair the long term prognosis. ${ }^{16}$ Secondly, hypertension is thought to accelerate coronary atherosclerosis, and it is possible that a high systolic pressure and a wide pulse pressure are associated with more extensive coronary atherosclerosis and hence poor outcomes. Neither the SAVE study ${ }^{15}$ nor the PREVENIR study ${ }^{13}$ reported coronary angiographic findings. Thirdly, a wide pulse pressure or a high systolic pressure may promote plaque rupture or fissuring, the proximate cause of acute coronary syndromes.

\section{ROLE OF BLOOD PRESSURE IN RISK STRATIFICATION AND MANAGEMENT}

Algorithms for risk stratification of patients with acute coronary syndromes have emphasised acute risk assessment, and have included age, haemodynamic response, evidence of ischaemia or necrosis, acute myocardial infarction location, history of acute myocardial infarction, height, and weight. In the GUSTO risk model the combination of diabetes, smoking, and history of hypertension accounted for only $2.5 \%$ of the risk of 30 day mortality, ${ }^{17}$ whereas in the TIMI risk score for non-ST elevation acute coronary syndromes, a combination of coronary risk factors including hypertension scores 1 out of a maximum score of $7 .{ }^{18}$ A history of hypertension also scores 1 point in the TIMI risk score for ST elevation myocardial infarction, which has a maximum score of $>8 .{ }^{19}$ In the LIPID study, which followed up survivors of acute coronary syndromes for six years, a history of hypertension was a significant multivariate risk factor for coronary heart disease, death or non-fatal myocardial infarction. ${ }^{20}$

A low ejection fraction ${ }^{16}$ and the presence of coronary artery stenosis ${ }^{18}$ have also been shown to be risk factors for poor outcomes. Early revascularisation is increasingly being used in the management of patients with acute coronary syndromes, ${ }^{21-23}$ and new antiarrhythmic treatments such as automatic defibrillators will be used increasingly to improve survival in selected patients. ${ }^{24}$ Whether the risk factors that were identified in an era with lower intervention rates still persist as risk factors despite these changes in practice will need to be assessed.

Recurrence of cardiac events is usually caused by plaque rupture or fissuring of lipid-rich minor plaques, ${ }^{25}$ and risk stratification and management will need to continue to focus on control of risk factors. The role of lipid lowering has been clearly established from multiple large scale trials, and the recent National Cholesterol Education Programme guidelines recommend that patients with elevated cholesterol levels should be started on aggressive lipid lowering treatment (aiming for a target value of $<2.5 \mathrm{mmol} / \mathrm{l}$ ) before hospital discharge, rather than waiting for the results of a three month dietary trial. ${ }^{26}$

Evidence based target values have not been specifically set for systolic pressure, diastolic pressure, and pulse pressures after acute coronary events, mainly because of a lack of data in this setting. In the HOT trial, which included 18790 patients (mean age 61.5 years) with diastolic pressures of 100$105 \mathrm{~mm} \mathrm{Hg}$ (7.5\% of whom had previous coronary disease), the lowest incidence of major cardiovascular events was observed in those who achieved a mean diastolic pressure of $83 \mathrm{~mm} \mathrm{Hg}$, and the lowest cardiovascular mortality was observed in those with a mean diastolic pressure of $86 \mathrm{~mm} \mathrm{Hg} .{ }^{27}$ Further reduction below these values did not significantly improve the risk reduction. These data cannot, however, be extrapolated directly to the majority of patients, who have predominantly systolic hypertension after myocardial infarction, ${ }^{15}$ as in the PREVENIR study. There is also concern 
that an excessive fall in diastolic pressure (to $<65 \mathrm{~mm} \mathrm{Hg}$ ) in patients with atherosclerosis, as can happen when the systolic pressure is being lowered by antihypertensive treatment, may actually increase the risk of myocardial infarction or stroke. $^{28} 29$

\section{TREATMENT OF HYPERTENSION AFTER AN ACUTE CORONARY EVENT}

Drugs that reduce blood pressure, such as $\beta$ blockers, are recommended for all patients without contraindications, and ACE inhibitors are recommended for patients without contraindications who have left ventricular systolic dysfunction. ACE inhibitors may have other properties in addition to their effects on left ventricular remodelling and blood pressure. Tissue specific ACE inhibitors have been shown to improve endothelial function. ${ }^{30}{ }^{31}$ In the HOPE study of 9297 patients who were at high risk of coronary disease and were not known to have heart failure or low ejection fractions, ramipril $(10 \mathrm{mg} /$ day) reduced the combined incidence of cardiovascular death, non-fatal myocardial infarction, and stroke by $22 \%$ over five years ( $14 \%$ with ramipril versus $17.8 \%$ with placebo, $\mathrm{p}<0.001)$. $^{32}$ However, the QUIET trial of 1750 patients without systolic dysfunction found that quinapril (20 mg/day) did not significantly improve outcomes. ${ }^{33}$ It should be noted that the QUIET trial excluded patients with hypertension, and the mean baseline blood pressure was $123 / 74 \mathrm{~mm} \mathrm{Hg}$, whereas in the HOPE study the mean baseline blood pressure was $139 / 79 \mathrm{~mm} \mathrm{Hg}$. The systolic and diastolic pressures both dropped by $3 \mathrm{~mm} \mathrm{Hg}$ in patients treated with ramipril in the HOPE study, and the benefit of ramipril was greater than would be expected from the magnitude of the blood pressure reduction. ${ }^{34}$ These data support the concept that patients with systolic hypertension after an acute coronary event should be considered for treatment with a tissue specific ACE inhibitor even if they have normal left ventricular function. Further data to strengthen or weaken this recommendation will soon be available from the PEACE ${ }^{35}$ and EUROPA $^{36}$ trials.

A major mechanism of systolic hypertension is the early return of the reflected pressure wave from the resistance arteries back to the central aorta in patients with stiff arteries. ${ }^{5}$ Specific treatments such as nitrates may alter the timing of this wave reflection, ${ }^{537}$ and have been recommended for elderly patients with isolated systolic hypertension. ${ }^{38}$

Hypertension is not the only risk factor to be poorly managed after an acute coronary event. At 1.4 years after the index event in the EUROASPIRE-II study, $21 \%$ of patients smoked, $31 \%$ were obese, $58 \%$ had total cholesterol concentrations of $\geqslant 5 \mathrm{mmol} / \mathrm{l}$, and $>70 \%$ of diabetics had inadequate glucose control (fasting blood sugar $\geqslant 7.0 \mathrm{mmol} / \mathrm{l}$ ). ${ }^{12}$ In addition, a large proportion of patients were not taking aspirin ( $14 \%$ ) or $\beta$ blockers (37\%).

Clearly we need to do better than this. Considerable effort has gone into developing the evidence to support modification of risk factors and specific drug treatments in patients who have suffered acute coronary syndromes. There is mounting evidence that after an acute coronary event, assiduous control of both systolic and diastolic pressure is also indicated.

\section{Authors' affiliations}

C-K Wong, H D White, Cardiovascular Research Unit, Green Lane Hospital, Auckland, New Zealand

\section{REFERENCES}

1 Staessen JA, Gasowski J, Wang JG, et al. Risks of untreated and treated isolated systolic hypertension in the elderly: meta-analysis of outcome trials. Lancet 2000;355:865-72.

2 Franklin SS, Larson MG, Khan SA, et al. Does the relation of blood pressure to coronary heart disease risk change with aging? The Framingham heart study. Circulation 2001;103:1245-9.
3 Domanski $M$, Mitchell G, Pfeffer $M$, et al. Pulse pressure and cardiovascular disease-related mortality: follow-up study of the multiple risk factor intervention trial (MRFIT). JAMA 2002;287:2677-83.

4 Franklin SS, Gustin W, Wong ND, et al. Hemodynamic patterns of age-related changes in blood pressure. The Framingham heart study. Circulation 1997:96:308-15.

5 Nicholls WW, O'Rourke MF. McDonald's blood flow in arteries: theoretical, experimental and clinical principles, 3rd ed. Philadelphia: Lea and Febiger, 1990:216-50.

6 Franklin SS, Khan SA, Wong ND, et al. Is pulse pressure useful in predicting risk for coronary heart disease? The Framingham heart study. Circulation 1999:100:354-60.

7 World Health Organization, International Society of Hypertension. 1999 World Health Organization - International Society of Hypertension guidelines for the management of hypertension: guidelines subcommittee. J Hypertens 1999;17:151-83.

8 JNC. The sixth report of the Joint National Committee on Prevention, Detection, Evaluation, and Treatment of High Blood Pressure. Arch Intern Med 1997; 157:2413-46.

9 Ramsay L, Williams B, Johnston G, et al. Guidelines for management of hypertension: report of the third working party of the British Hypertension Society. J Hum Hypertens 1999;13:569-92.

10 Benetos A, Thomas F, Bean K, et al. Prognostic value of systolic and diastolic blood pressure in treated hypertensive men. Arch Intern Med 2002; 162:577-81

11 Mancia G, Bombelli M, Lanzarotti A, et al. Systolic vs diastolic blood pressure control in the hypertensive patients of the PAMELA population. Arch Intern Med 2002;1 62:582-6.

12 EUROASPIRE II Investigators. Lifestyle and risk factor management and use of drug therapies in coronary patients from 15 countries: principal results from EUROASPIRE II Euro heart survey programme. Eur Heart J 2001;22:554-72.

13 Amar J, Chamontin B, Ferrieres J, et al. Hypertension control at hospital discharge after acute coronary event: influence on cardiovascular prognosis - the PREVENIR study. Heart 2002;88:587-91

14 Benetos A, Adamopoulos C, Bureau JM, et al. Determinants of accelerated progression of arterial stiffness in normotensive subjects and in treated hypertensive subjects over a 6-year period. Circulation 2002; 105: 1202-7.

15 Mitchell GF, Moyé LA, Braunwald E, et al. Sphygmomanometrically determined pulse pressure is a powerful independent predictor of recurrent events after myocardial infarction in patients with impaired left ventricular function. Circulation 1997:96:4254-60.

16 White HD, Norris RM, Brown MA, et al. Left ventricular end-systolic volume as the major determinant of survival after recovery from myocardial infarction. Circulation 1987;76:44-51

17 Lee KL, Woodlief LH, Topol EJ, et al. Predictors of 30-day mortality in the era of reperfusion for acute myocardial infarction: results from an international trial of 41,021 patients. Circulation 1995:91:1659-68.

18 Antman EM, Cohen M, Bernink PJLM, et al. The TIMl risk score for unstable angina/non-ST elevation MI: a method for prognostication and therapeutic decision making. JAMA 2000;284:835-42.

19 Morrow DA, Antman EM, Charlesworth A, et al. TIMl risk score for ST-elevation myocardial infarction: a convenient, bedside, clinical score for risk assessment at presentation: an intravenous nPA for treatment of infarcting myocardium early II trial substudy. Circulation 2000;102:2031-7

20 Marschner IC, Colquhoun D, Simes RJ, et al. Long-term risk stratification for survivors of acute coronary syndromes: results from the long-term intervention with pravastatin in ischemic disease (LIPID) study. J Am Coll Cardiol 2001;38:56-63.

21 Fragmin and Fast Revascularisation During Instability in Coronary Artery Disease (FRISC II) Investigators. Invasive compared with non-invasive treatment in unstable coronary-artery disease: FRISC II prospective randomised multicentre study. Lancet 1999-354:708-15.

22 Cannon CP, Weintraub WS, Demopoulos LA, et al. Comparison of early invasive and conservative strategies in patients with unstable coronary syndromes treated with the glycoprotein Ilb/Illa inhibitor tirofiban. N Engl J Med 2001;344:1879-87.

23 Stone GW, Grines CL, Cox DA, et al. Comparison of angioplasty with stenting, with or without abciximab, in acute myocardial infarction. $N$ Engl J Med 2002;346:957-66

24 Moss AJ, Zareba W, Hall WJ, et al. Prophylactic implantation of a defibrillator in patients with myocardial infarction and reduced ejection fraction. N Engl J Med 2002;346:877-83.

25 Davies MJ. The pathophysiology of acute coronary syndromes. Heart 2000;83:361-6

26 National Cholesterol Education Program. Executive summary of the third report of the National Cholesterol Education Program (NCEP) expert panel on detection, evaluation, and treatment of high blood cholesterol in adults (adult treatment panel III). JAMA 2001;285:2486-97.

27 Hansson L, Zanchetti A, Carruthers SG, et al. Effects of intensive blood-pressure lowering and low-dose aspirin in patients with hypertension: principal results of the hypertension optimal treatment (HOT) randomised trial. Lancet 1998;351:1755-62.

28 Somes GW, Pahor M, Shorr Rl, et al. The role of diastolic blood pressure when treating isolated systolic hypertension. Arch Intern Med 1999; 159:2004-9.

29 Voko Z, Bots ML, Hofman A, et al. J-shaped relation between blood pressure and stroke in treated hypertensives. Hypertension 1999:34:1181-5.

30 Mancini GBJ, Henry GC, Macaya C, et al. Angiotensin-converting enzyme inhibition with quinapril improves endothelial vasometer 
dysfunction in patients with coronary artery disease. The TREND (trial on reversing endothelial dysfunction) study. Circulation 1996;94:258-65.

31 Anderson TJ, Elstein E, Haber H, et al. Comparative study of

ACE-inhibition, angiotensin II antagonism, and calcium channel blockade on flow-mediated vasodilation in patients with coronary disease (BANFF study). J Am Coll Cardiol 2000;35:60-6.

32 Yusuf S, Sleight $P$, Pogue J, et al. Effects of an angiotensin-converting-enzyme inhibitor, ramipril, on cardiovascular events in high-risk patients. The heart outcomes prevention evaluation study investigators [published erratum appears in N Engl J Med 2000;342:748]. N Engl J Med 2000;342:145-53.

33 Pitt B, O'Neill B, Feldman R, et al. The quinapril ischemic event trial (QUIET): evaluation of chronic ACE inhibitor therapy in patients with ischemic heart disease and preserved left ventricular function. Am J Cardiol 2001;87:1058-63.
34 Sleight $\mathbf{P}$, Yusuf $S$, Pogue J, et al. Blood-pressure reduction and cardiovascular risk in HOPE study. Lancet 2001;358:2130-1.

35 Pfeffer MA, Domanski M, Rosenberg Y, et al. Prevention of events with angiotensin-converting enzyme inhibition (the PEACE study design). Prevention of events with angiotensin-converting enzyme inhibition. Am J Cardiol 1998;82:25H-30H.

36 Fox KM, Henderson JR, Bertrand ME, et al. The European trial on reduction of cardiac events with perindopril in stable coronary artery disease (EUROPA). Eur Heart J 1998;19(suppl J):J52-5

37 Duchier J, lannascoli F, Safar M. Antihypertensive effect of sustained-release isosorbide dinitrate for isolated systolic systemic hypertension in the elderly. Am J Cardiol 1987;60:99-102.

38 Safar ME. Epidemiological findings imply that goals for drug treatment of hypertension need to be revised. Circulation 2001;103:1188-90.

\section{IMAGES IN CARDIOLOGY}

\section{Resolution of renal artery thrombus with direct administration of tissue plasminogen activator}

A 61 year old woman with a background history of systemic hypertension, hyperlipidaemia, recurrent episodes of flash pulmonary oedema (four episodes in two years), normal left ventricular systolic function on echocardiography, normal stress testing, and angiographically normal coronary arteries underwent renal angiographic studies. The right renal artery was normal. There was a high grade ostial lesion affecting the left renal artery with intraluminal thrombus (top panel). The thrombus resolved following direct intra-arterial administration of $10 \mathrm{mg}$ of recombinant tissue plasminogen activator (middle panel). The ostial lesion was successfully stented with a $6 \times 14 \mathrm{~mm}$ stent following predilatation with a $5 \times 20 \mathrm{~mm}$ balloon. An excellent angiographic result was obtained (bottom panel). An angiotensin converting enzyme inhibitor was successfully introduced following the intervention leading to better blood pressure control and resolution of the episodes of pulmonary oedema.

Significant renovascular disease must be suspected in all patients presenting with "flash" pulmonary oedema and normal left ventricular systolic function. Successful intervention often leads to complete resolution of these episodes.
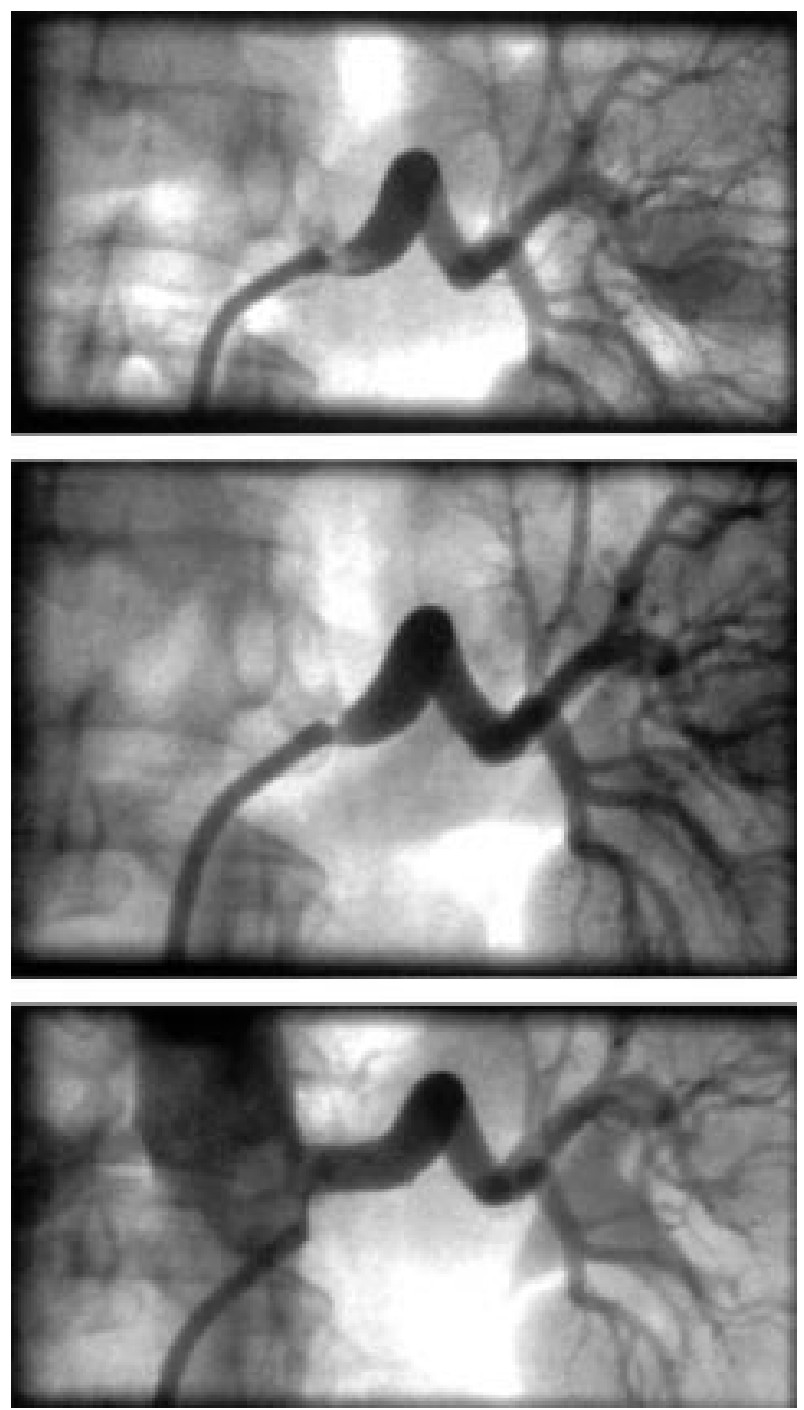

achandran ow. scot.nhs.uk 